\title{
Psychological Capital Questionnaire (PCQ-24): Preliminary Evidence of Psychometric Validity of the Brazilian Version
}

\author{
Daren Tashima Cid ${ }^{1}$ \\ Maria do Carmo Fernandes Martins ${ }^{1}$ \\ Maiango Dias ${ }^{1}$ \\ Andrea Cristina Fermiano Fidelis ${ }^{2}$ \\ ${ }^{1}$ Universidade Metodista de São Paulo \\ ${ }^{2}$ Universidade de Aveiro
}

\begin{abstract}
The PCQ-24 is the main international measure for assessing psychological capital (PsyCap) in organizational contexts. In order to evaluate its adaptation to the Brazilian context, this study aimed to verify preliminary evidences of its psychometric validity. Data collection was conducted online with 749 employees from all regions of Brazil. Confirmatory factor analysis was performed to examine the quality of fit of the second-order factor structure of PCQ-24. The fit indicators were satisfactory $(\chi 2=$ $742.10, \chi 2 / \mathrm{df}=4.01, \mathrm{p}<.001, \mathrm{SRMR}=.05, \mathrm{CFI}=.91, \mathrm{GFI}=.90, \mathrm{TLI}=.90, \mathrm{RMSEA}=.06)$. Cronbach's alpha was .92 and the composite reliability coefficient was .95; in addition, a multigroup confirmatory factorial analysis, comparing male and female participants, demonstrated that the scale is adequate for both groups. These results indicate, in a preliminary way, the validity of PCQ-24 as a measure of psychological capital in the Brazilian labor context.

Keywords: psychological capital; positive psychology; PCQ-24; organizational behavior; confirmatory factor analysis.
\end{abstract}

\section{Questionário de Capital Psicológico (PCQ-24): Evidências Preliminares de Validade Psicométrica da Versão Brasileira}

\begin{abstract}
Resumo
O PCQ-24 é a principal medida internacional para avaliação do capital psicológico nos contextos organizacionais. Para verificar sua adaptação à realidade brasileira, este estudo objetivou testar evidências preliminares de validade psicométrica. Foi conduzida coleta de dados on-line, com 749 trabalhadores, de todas as regiões do Brasil. Os dados foram submetidos à análise fatorial confirmatória, para examinar a qualidade de ajustamento da estrutura de segunda ordem do PCQ-24. Os indicadores de ajuste foram satisfatórios $(\chi 2=742,10 ; \chi 2 / d f=4,01, p<0,001$; $\mathrm{SRMR}=0,05 ; \mathrm{CFI}=0,91$; GFI = 0,90; TLI = 0,90, RMSEA = 0,06). O alfa de Cronbach foi de 0,92 e o coeficiente de confiabilidade composta foi de 0,95 ; análise fatorial confirmatória multigrupos (AFCMG) para homens e mulheres demonstrou que a escala é adequada para ambos os grupos. Tais resultados indicam evidências preliminares de validade do PCQ-24, como medida de capital psicológico em contexto laboral brasileiro.

Palavras-chave: capital psicológico, psicologia positiva, PCQ-24, comportamento organizacional, análise fatorial confirmatória
\end{abstract}

\section{Cuestionario de Capital Psicológico (PCQ-24): Evidencias Preliminares de Validez Psicométrica de la Versión Brasileña}

\begin{abstract}
Resumen
El PCQ-24 es la principal medida internacional para evaluación del capital psicológico en contextos organizacionales. Para verificar su adaptación a la realidad brasileña, este estudio tuvo como objetivo probar evidencias preliminares de validez psicométrica. Fue realizada recolección de datos online de 749 trabajadores de todas las regiones de Brasil. Los datos fueron sometidos a análisis factorial confirmatoria para examinar la calidad de ajuste de la estructura de segundo orden del PCQ-24. Los indicadores de ajuste fueron satisfactorios $(\chi 2=742,10, \chi 2 / \mathrm{df}=4,01, \mathrm{p}<0,001, \mathrm{SRMR}=0,05, \mathrm{CFI}=0,91, \mathrm{GFI}=0,90$, TLI $=0,90, \mathrm{RMSEA}=$ 0,06). El alfa de Cronbach fue de 0,92 y el coeficiente de confiabilidad compuesta fue de 0,95 ; análisis factorial confirmatorio multigrupos AFCMG, para hombres y mujeres, demostró que la escala es adecuada para ambos grupos. Estos resultados indican evidencias preliminares de validez del PCQ-24, como medida de capital psicológico en el contexto laboral brasileño.

Palabras clave: capital psicológico; psicología positiva; PCQ-24, comportamiento organizacional; análisis factorial confirmatorio
\end{abstract}

\section{Introduction}

Psychological Capital (PsyCap) is a positive psychological state of development, characterized by a set of congruent resources (Luthans \& Youssef, 2004). These resources are: self-efficacy (Bandura, 1997), which refers to an individual's confidence in their capabilities, their potential for achievement, and their ability to maintain and invest the necessary efforts to succeed in challenging tasks; optimism (Seligman, 1998) refers to a tendency to attribute positive events to internal, permanent and universal causes, while negative events 
tend to be attributed to external, temporary and specific causes; hope (Snyder, 2000), refers to persist towards goals and, if necessary, redirect ways or means by which they may be achieved; and resilience (Masten, 2001) refers to the ability to overcome problems, adversities or even positive challenges, but which seem very difficult (such as assuming a position of high responsibility).

The four dimensions operate synergistically, becoming a single component, acting in an integrated and interactive way, increasing the probability of success in the actions of the individuals, being associated with greater effort, motivation and perseverance in the performance within the organizations (Avey, Luthans, Smith, \& Palmer, 2010). However, self-efficacy, optimism, hope and resilience are constructs that also have unique characteristics, with discriminant validity between them, differentially impacting on productivity, attitudes, behaviors, health and well-being (Luthans \& Avolio, 2014; Luthans \& Youssef, 2007; Luthans \& Youssef-Morgan, 2017; Luthans, Youssef-Morgan, \& Avolio, 2015).

The composition of these four elements was proposed as the key to PsyCap, a construct that refers to 'who you are and who you are becoming', in the sense of openness to the development of the psychological state. This definition seeks to differentiate it from the concepts of human capital, or 'what you know' (competencies), and social capital, or 'who you know' (network of relationships).
The main background and consequent variables of PsyCap, at the individual and organizational levels, widely valued in the context of people management, are summarized in Figure 1 (Avey, Luthans, \& Jensen, 2009; Avey, Reichard, Luthans, \& Mhatre, 2011; Cavalcante, Siqueira, \& Kuniyoshi, 2015; Newman, Ucbasaran, Zhu, \& Hirst, 2014; Paterson, Luthans, \& Jeung, 2014). In addition to the work environment, the consequences of a high PsyCap have been related to indicators of health and personal development (Dollwet \& Reichard, 2014; Krasikova, Lester, \& Harms, 2015; Luthans, Youssef, Sweetman, \& Harms, 2013; Naotunna, 2015; Reichard, Dollwet, \& Louw-Potgieter, 2014). To assess PsyCap, these studies have used different instruments, which will be characterized next.

\section{The measure of PsyCap}

There are different validated instruments for PsyCap, based in empirical evidence. Luthans, Avolio, Avey and Norman (2007) developed the Psychological Capital Questionnaire - PCQ-24, the main instrument used to measure the construct. Subsequently, Harms and Luthans (2012) developed the Implicit Psychological Capital Questionnaire (I-PCQ) to help minimize problems related to social desirability in self-report instruments; Lorenz, Beer, Pütz and Heinitz (2016) also developed and validated a measure for PsyCap (CPC12), with applications for all domains of life, not only

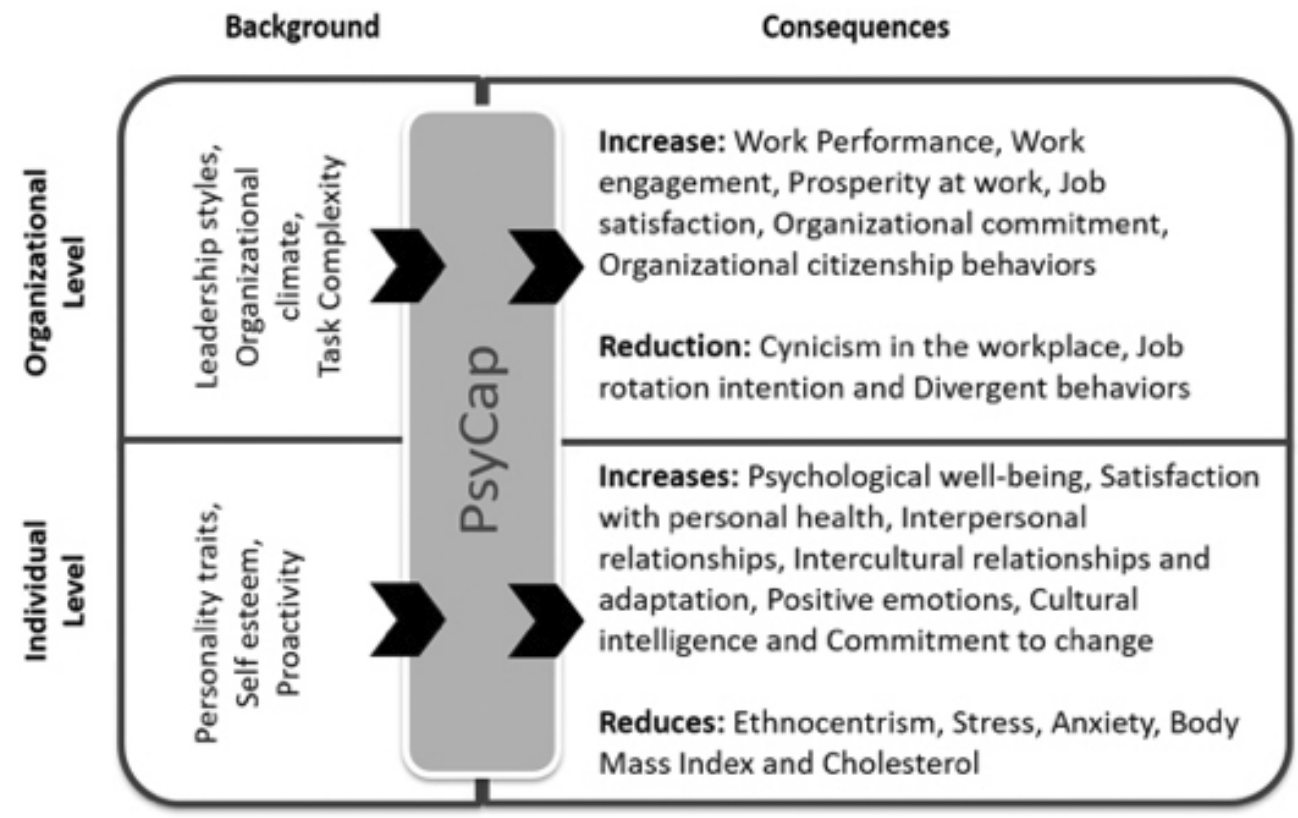

Figure 1. Main background and consequent variables of PsyCap, at the individual and organizational levels. 
the organizational context. The PCQ-24 itself and its reduced version (PCQ-12) were adapted to contexts other than the workplace, such as health and relationships (Luthans et al., 2013). Siqueira, Martins and Souza (2014) validated a PsyCap scale, the Inventory of Psychological Capital (ICPT-25) and its reduced form (ICPT-12), for the Brazilian context.

However, in the international context, the Psychological Capital Questionnaire, in its complete (Luthans, Avey, Clapp-Smith, \& Li, 2008), and reduced (Luthans, Avey, Clapp-Smith, \& Li, 2008) versions, PCQ-24 and PCQ-12, with 24 and 12 items, respectively, can be considered as virtually hegemonic. The PCQ-24 was originally developed from the adaptation of clinical scales of self-efficacy, optimism, hope and resilience, whose theoretical and methodological bases are anchored in the assumption of positive psychological state, open to change, and its evaluation can be applied to the workplace context.

Luthans et al., (2007) collected four scales that met these criteria: the Snyder et al., (1996), Wagnild and Young's (1993) resilience, Scheier and Carver's optimism (1985) and Parker's self-efficacy scale (1998). To emphasize the transient state of PsyCap, the authors ask the PCQ-24 respondents to indicate "how they see themselves at that moment". The original version of the instrument was proposed and confirmed (Luthans et al., 2007), by confirmatory factorial analysis. The best model fit was the four-factor model, with six items each. The final version is evaluated on a six-point Likert scale, ranging from "strongly disagree" to "strongly agree" with Cronbach's alphas between 0.66 and 0.89 .

The hope factor includes items about its two facets, "agency" and "pathways," with items such as "I am now achieving the professional goals I set for myself" and "I can think of many ways to achieve my goals at work". The self-efficacy factor includes items related to perceived individual abilities, such as "I feel able to help set goals for my field of work." The optimism factor includes items that demonstrate the tendency to assign positive events to internal, permanent and comprehensive causes, such as "at work, I am optimistic about what will happen to me in the future." Finally, the items of the resilience factor indicate a capacity to recover from adversities and failures, such as "I am able to overcome difficult moments at work because I have been through difficulties before."

The PCQ-12, reduced version of the PCQ-24, was developed by Luthans et al., (2008), using 12 original PCQ-24 items, chosen among those with the highest factor load, which contributed the most to the reliability, which kept the different facets of the underlying constructs and that maximized the construct amplitude. The instrument included three items for effectiveness, three for resilience, two for optimism, and four items for hope (including the two facets of the factor).

Luthans and Youssef-Morgan (2017) valued the instrumentality of PCQ-12, especially in complex research protocols. The PCQ-12 does not have items with inverted scores, as it happens in the PCQ-24. Studies like Dawkins, Martin, Scott and Sanderson (2013) suggest that inverted items tend to be problematic, particularly in the evaluation of positive phenomena.

To evaluate the psychometric studies involving PsyCap, Dawkins et al., (2013) made a systematic review on the subject, with 29 studies using the different versions of the PCQ. In the comparison of the results of the exploratory and confirmatory analyzes, the PCQ-24 and PCQ-12 scales showed significant reliability (internal consistency higher than 0.70 ) in different cultural and organizational contexts, indicating the potential of the instrument to measure the PsyCap. Their conclusions support the robustness of the statistical results found; despite indicating that the presence of inverted items, in the optimism and resilience dimensions, contribute to decrease the performance of the scale.

Studies with the objective of validating PCQ24 were carried out in several countries, such as USA (Luthans et al., 2007), South Africa (Du Plessis \& Barkhuizen, 2012, Görgens-Ekermans \& Herbert, Dominguez, Moriano, \& Molero, 2014), China (Qingshan, Le, \& Xuansheng, 2014) and Portugal (Antunes, Caetano, \& Pina-Cunha, 2017), among others. Most of the studies corroborate the original structure of the instrument, with the distribution in four factors, with correlations between the factors varying between 0.36 and 0.77 , and Cronbach's alphas between 0.80 and 0.90 .

Some confirmatory factor analyzes of PCQ-24 and PCQ-12 have shown that the model and dimensions fit best when PsyCap is considered a second-order factor (Avey, Luthans, \& Mhatre, 2008; Azanza, et al., Luthans, Youssef, \& Avolio, 2007, Rus, Baban, Jesus, \& Andrey, 2012, Sapyaprapa, Tuicomepee, \& Watakakosol, 2013, Stajkovic, 2006). However, the results are not consensual and conclusive regarding how the construct's factorial structure is established.

Other studies, such as Antunes et al., (2017) and Rego, Marques, Leal, Souza and Pina-Cunha (2010), revealed that the model that best fits the data was constituted by five factors, starting from a division 
of the hope dimension into two subfactors. Duplessis and Barkhuizen (2012), on the other hand, found three factors in PCQ-24 (optimism, resilience, and a fusion between hope and self-efficacy). To verify the invariance of the PCQ-12, Wernsing (2014) applied the instrument to employees of the same company in 12 different countries, including Brazil; the results of the study pointed to a better fit of the three-factor model, with the elimination of the optimism factor. In this solution, internal consistency was acceptable in all countries, with Cronbach's alpha coefficient ranging from 0.84 to 0.92 .

In some studies, the best factorial fit occurs when PsyCap is interpreted as a first order correlational model with four factors (Çetin \& Basim, 2012; Formiga, Viseu, \& Neves de Jesus, 2014; Viseu et al., 2012). Formiga, Viseu and Neves de Jesus (2014) used a version of PCQ-12, validated by Viseu et al., (2012) for the Portuguese context, in Brazilian workers. The results of the confirmatory analysis, in both cases, found the 4-factor solution for the scale, which reached reasonable reliability in this population (alphas between 0.64 and 0.82 , lambdas between 0.70 and 0.87 ). Due to the oscillation of factorial solutions, Rego et al., (2010) raised the hypothesis that PsyCap may behave differently according to cultural aspects.

Recently, Kamei et al., (2018) presented robust evidence of validity of the PCQ-12 in the Brazilian context. The results showed fit indexes for a secondorder structure, with a general psychological capital factor explaining the four first-order factors (CFI = 0.95$, TLI $=0.94$, RSMR $=0.04$, RMSEA $=0.06)$. The PCQ-12 invariance (configural, metric and scalar) in multi-factorial analyzes for different samples (men and women, young adults and elderly) demonstrated by this study indicates that the PCQ-12 had good psychometric properties and it can be used in a wide range of samples in the Brazilian context.

Some evidences of validity of the PCQ-24 in the Brazilian context were obtained by Raulino (2015), who made a cross-cultural adaptation of the instrument. The exploratory factor analysis, however, presented some inconsistencies: with orthogonal rotation, the data indicated an initial solution of five factors, with the fifth factor corresponding to the inverse items of the scale. With the withdrawal of six items (with a lower factor load, cross loads between factors and without theoretical explanation), the author obtained a final solution of four factors, with Cronbach's alphas between 0.73 and 0.83 , explaining $62 \%$ of the total variance.
Fidelis (2016) also performed an exploratory factorial analysis of the PCQ-24 finding Cronbach's alphas between 0.82 and 0.92 , in four factors, which explained $69 \%$ of the total variance. However, also in this study, the factorial solution depended on the exclusion of items with an inverse sense of scale, reducing it to 21 items; furthermore, one of the resilience items clustered to the hope factor. It is noteworthy that the studies that sought scale adaptation in Brazil were conducted in very specific samples of health professionals from one state (Fidelis, 2016) and managers of a health cooperative from another state (Raulino, 2015), which may have contributed to the reduction of variance in the sample, and possible biases in the results.

Therefore, there are inconsistencies in national and international studies on the PCQ-24 factor solution. In addition, there are no confirmatory studies validating a Brazilian version of PCQ-24. Considering the importance of expanding the possibilities of evaluation of the construct in Brazil, the possibility of promoting cross-cultural comparative studies on PsyCap with single databases, as well as the possibility of performing convergent studies with other instruments, this study aims to verify preliminary evidence of psychometric validity, through a confirmatory factorial analysis, of the PsyCap - PCQ - 24 questionnaire for the Brazilian reality, based on its original items.

\section{Method}

\section{Participants}

This study counted on the voluntary participation of 749 Brazilian workers, meeting the criteria regarding the size of the required sample, of at least 10 to 15 observations per manifest variable (Kline, 2015). Participants were distributed in the Southeast (67\%), Midwest $(16 \%)$, South $(10 \%)$, Northeast $(4 \%)$ and North $(3 \%)$ regions. Most of them were female $(65.3 \%)$, aged between 26 and 35 years (34.8\%, mean age 32, SD $=10)$, single $(48.5 \%)$ and with high educational level (49.5\% post-graduates). It was verified that almost all the respondents were working $(94.5 \%)$, with a formal contract $(48.7 \%)$, in private companies $(57.4 \%)$, with more than 100 employees (54\%), although working for less than five years in the same company (70.4\%).

The most represented occupational groups in the sample were higher education professionals (37.7\%), administrative service or office workers (13.9\%), traders and service providers (10.3\%) and senior high school, technical, or vocational level $(9.5 \%)$. A significant 
proportion $(36.3 \%)$ of the respondents were in leadership positions.

\section{Instruments}

This study used two instruments, a socio-occupational questionnaire and the translated Portuguese version of the Psychological Capital Questionnaire - PCQ-24 (Luthans et al., 2007). The socio-occupational questionnaire was developed by the authors, asking the participants to identify personal and professional characteristics, in order to allow greater scrutiny of the data.

The PCQ-24 seeks to assess the four dimensions of PsyCap: self-efficacy, hope, optimism, and resilience. The instrument is originally composed of 24 items, associated to a six-point Likert scale, ranging from 1 - "strongly disagree" to 6 - "strongly agree". This questionnaire was adapted transculturally to the Brazilian context by Raulino (2015) and Fidelis (2016), in studies that used reverse translations of the original in English, with final versions validated by experts. In both studies, the empirical structure was tested by exploratory factorial analysis, with different solutions, but always with the removal of the items with reverse meaning.

Considering the inconsistencies of the Raulino (2015) and Fidelis (2016) versions, this study recomposed the PCQ-24 with its 24 original items translated by these authors. This decision was due to the analysis of the focus group carried out with experts (postgraduate students in Psychology), who suggested the reincorporation of the excluded items, for testing in a more heterogeneous sample, since the two available studies were performed in very specific samples.

\section{Proceedings}

\section{Data collection}

Data collection was initiated after approval by the Research Ethics Committee of Universidade Metodista de São Paulo, CAAE 61114216.6.0000.5508 and authorization for application of the PCQ-24 by the Mind Garden publishing house (Copyright (C) 2007 Psychological Capital Questionnaire - all rights reserved), who requested that the items of the instrument not be disclosed in their entirety. The collection was completed through a link of the research, published in social and professional networks. The research protocol was inserted in a virtual platform of data collection, with access after agreement to the free and informed consent form.

\section{Data Analysis}

Data analysis was performed in two stages: (1) confirmatory factorial analysis (CFA), maximum likelihood method (ML), with the support of AMOS software (v.22) and SPSS (v.22), to examine the quality of fit indices of the second-order factor structure of PCQ24 , considering the existence of a psychological theory based on international theoretical and empirical studies on the factor structure of the instrument, and (2) analysis of the internal consistency obtained by Cronbach's alpha coefficients and by composite reliability.

We analyzed the assumptions for the use of the technique to avoid skewed results of model fit statistics, estimates and significance of the parameters. The normal, univariate and multivariate distribution of values was verified by the asymmetry coefficients $(\mathrm{Sk}<3)$ and kurtosis $(\mathrm{Ku}<7)$. The extreme values were evaluated by the Mahalanobis distance (Kline, 2015).

To assess the goodness of fit indices of the proposed model, the chi-square $\left(\chi^{2}\right)$ values and the ratio between the values of chi-square and degrees of free$\operatorname{dom}\left(\chi^{2} / d f\right)$ were used. Since $\chi^{2}$ is very sensitive to sample size and deviations from normality, other fit indices were considered: CFI (Comparative Fit Index), GFI (Goodness-of-Fit Index), TLI (TuckerLewis Index), SRMR (Standardized Root Mean Square Residual) and RMSEA (Root Mean Square Error of Approximation). We adopted as criteria of satisfactory fit the indicators of $\chi^{2} / \mathrm{df}$ values under 5 ; the adhesion indexes CFI, GFI and TLI with values greater than 0.90; SRMR lower than 0.08 and RMSEA near or below 0.08 (Arbuckle, 2013, Hair, Black, Babin, Anderson \& Tatham, 2010, Marôco, 2014). We also used the AIC (Akaike Information Criterion) and MECVI (Modified Expected Cross-Validation Index) indices to compare different fit models; in these cases, the best fit of the model is the one that obtains the lowest index.

In order to evaluate whether the factor structure of the PCQ-24 is invariant for groups separated by sex, we used Multigroup confirmatory factor analysis (MCFA). The invariance of the model was evaluated in both groups by comparing the free model with a model with factor weights, covariance and fixed intercepts, to test the metric and scalar invariance. The differences between the model fit indexes were assessed using the chi-square $\left(\Delta \chi^{2}<0.05\right)$ and CFI $(\Delta \mathrm{CFI})$ difference. To assume measurement invariance, the model tested should not show differences in the IFC $(\Delta \mathrm{CFI}>0.01)$. We chose not to evaluate the residual invariance of the items because of the lack of consensus about their 
need and because it is a restrictive procedure that is difficult to reach in Psychology research (Damásio, 2013).

\section{Results}

To reach the objective, we tested the PCQ-24 model with a 2 nd order factor structure proposed by Luthans et al., (2007). In the first analysis, with 24 items, the original model showed a satisfactory fit (Table 1). However, the three inverted items had factor loads below 0.45 (0.18, 0.07 and 0.23$)$, the minimum value required for confirmatory factor analyzes, according to Tabachnick and Fidell (2013), besides presenting signal correlations contrary to the theoretically expected.

From the withdrawal of the three inverse items, the PCQ-24 scale was changed to 21 items (self-efficacy $=6$, hope $=6$, resilience $=5$ and optimism $=4)$. In this new model, most variables presented asymmetric distribution, with skewness values between -0.43 and -1.34, and kurtosis between -0.81 and 2.06; however, such values do not deviate excessively from those considered adequate for the assumption of normality and correspond to the accepted criteria for the use of the ML method. Mahalanobis distances did not indicate the presence of multivariate extreme values, which could interfere in the results (Kline, 2015, Marôco, 2014). After analyzing the assumptions, satisfactory fit indices were obtained (Table 1); it is estimated that the confirmatory factor analysis of this second-order model revealed a higher fit, even though it was not necessary to apply any indexes of modifications.

Considering the sample size, greater than 300, parsimony indexes (Parsimony CFI, Parsimony GFI and Parsimony NFI) were also evaluated, compensating the improvement of the fit of the model by the inclusion of more free parameters (PCFI $=0.80$, PGFI $=0.73$ and PNFI $=0.78)$, whose values, between 0.60 and 0.80 , maintain the indicative of good fit of the model (Marôco, 2014). The results also showed that the items of the scale present factor loads adequate to factor increases, between 0.50 and 0.82 , all of which are statistically significant.
Marôco (2014) warned that in the validation of a psychometric instrument, any modification of the original version should be submitted to validation with the AIC and MECVI indexes, in ML method. Thus, for the two models tested, the one with 21 items (without the reverse items) had lower values of MECVI $=1.11$ and $\mathrm{AIC}=834.10$, in relation to the 24-item model (MECVI $=1.46$ and AIC $=1094.10$ ), that is, it presents better external validity and stability in an independent sample.

In addition to the quality indexes of the overall model fit, Cronbach's alpha and composite reliability (CR) coefficients were analyzed. The alpha results were satisfactory for the second-order model $(\alpha=0.92)$ and for all first-order factors (self-efficacy $\alpha=0.85$; hope $\alpha=0.81$; resilience $\alpha=0.75$; and optimism $\alpha=0.78$ ), indicating a consistent and reliable instrument, with alphas of at least 0.70 (Tabachnick \& Fidell, 2013).

$\mathrm{CR}$ has been presented as a more robust accuracy indicator when compared to the alpha coefficient, being used to evaluate the quality of the structural model of a psychometric instrument. The results indicated a CR $=0.95$ for the full scale (self-efficacy $=0.85$, hope $=$ 0.82 , resilience $\alpha=0.76$ and optimism $\alpha=0.79$ ), above the reference value of 0.70 , considered an indicator of good construct reliability (Hair et al, 2010; Marôco, 2014; Valentini \& Damásio, 2016).

Based on these results, we opted for the secondorder model of 21 items that presented the best fit and allows us to calculate the results of both the four factors individually and the second-order factor, PsyCap, all of them with good reliability indexes. Figure 2 shows the structure of the model.

The results (Table 2) of the multigroup confirmatory factor analysis (MCFA) revealed that the factor model of the PCQ-24 presents a good fit for male and female sexes, demonstrating its configurational invariance. Regarding the invariance of the parameters between the male and female groups, it was observed that the model with fixed factor weights has a fit with small and practically negligible differences in the analyzed indicators, when compared to the free model $\left(\chi^{2} /\right.$

Table 1.

Fit Indices of the PCQ-24 models.

\begin{tabular}{lccccccccc}
\hline Models & $\chi^{2}$ & $\chi^{2} / \mathrm{df}$ & CFI & GFI & TLI & SRMR & RMSEA & Alpha & CR \\
\hline Model 1 & 990.10 & 3.99 & 0.88 & 0.89 & 0.87 & 0.05 & 0.06 & 0.90 & 0.96 \\
Model 2 & 742.10 & 4.01 & 0.91 & 0.90 & 0.90 & 0.05 & 0.06 & 0.92 & 0.95 \\
\hline
\end{tabular}




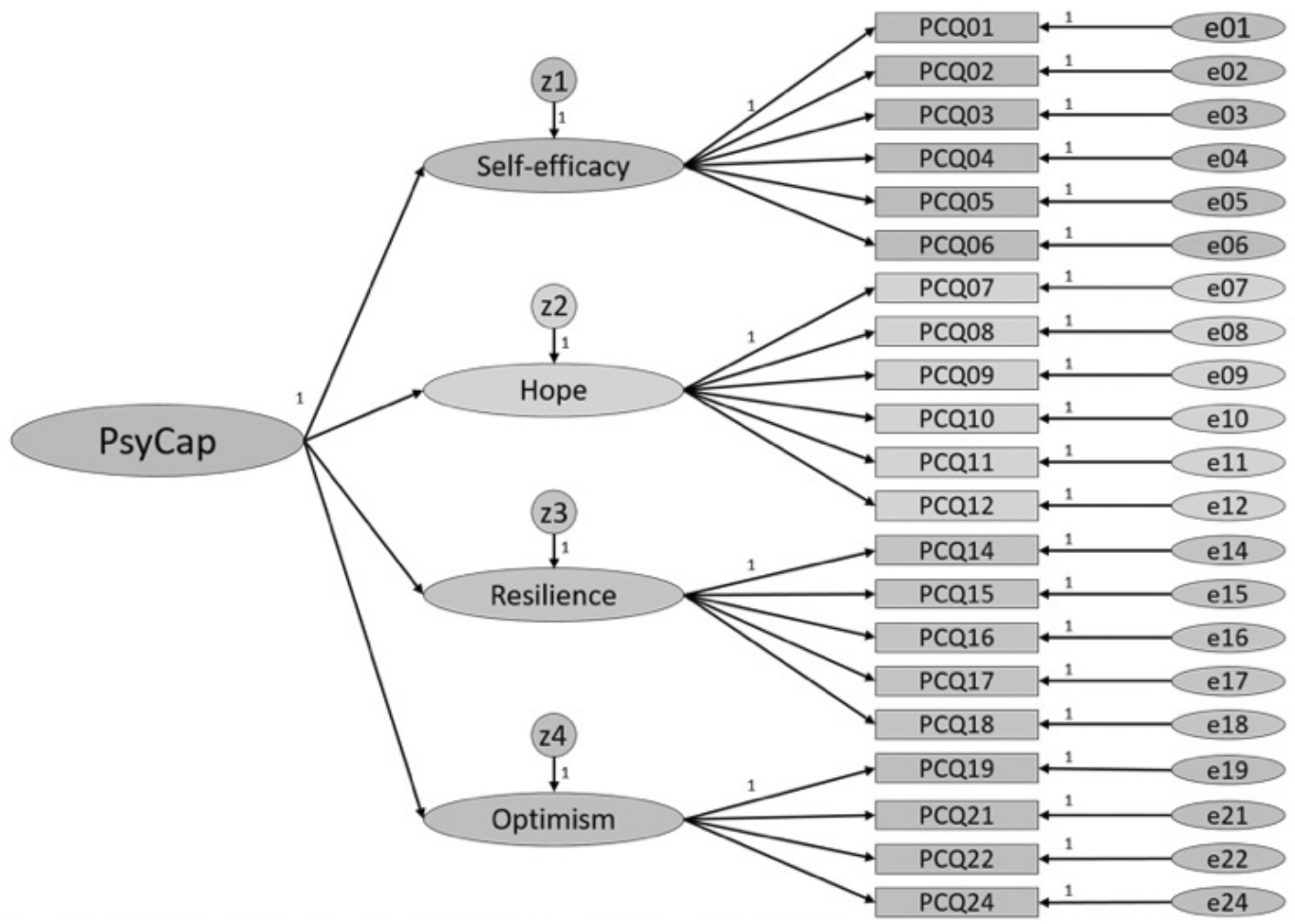

Figure 2. Second-order structure of the PCQ-24 with 21 items.

$\mathrm{df}=2,672, \mathrm{CFI}=0.90, \mathrm{PCFI}=0.83, \mathrm{RMSEA}=0.047$, C.I. $90 \%[0.044,0.051])$.

The quality of fit of the two models is not significantly different. At $\mathrm{p}=0.245$, we do not rule out the hypothesis that the model with fixed factor weights fits as well to both groups as the model with free factor weights, that is, the model has a weak invariance, thus demonstrating the metric invariance of factorial weights in the two groups. Female and male participants respond to items in a similar way, and there are no significant response biases to one or more items.

The scalar invariance test of intercepts is another aspect necessary to compare scores between groups.
The results of the scalar invariance analysis $(\mathrm{DF}=21$, $\mathrm{CMIN}=43.85, \mathrm{p}=0.425)$ show that the intercepts are invariant between men and women, presenting strong measure invariance.

\section{Discussion}

Previous analysis of the PCQ-24 indicated that the exclusion of the reversed items increases the factor load of the other items and increases the model fit (Çetin \& Basim, 2012; Chen \& Lim, 2012; Rego et al., 2010). These results are equivalent to those of the only two exploratory factor analyzes performed with

Table 2.

Multi-group Confirmatory Factor Analysis of PCQ-24 for the Sex Variable.

\begin{tabular}{lccccc}
\hline \multirow{2}{*}{ Groups } & \multicolumn{5}{c}{ Fit Quality Index (GFI) } \\
\cline { 2 - 6 } & $\chi^{2}(\mathrm{df})$ & CFI & PCFI & RMSEA $(90 \% \mathrm{CI})$ & $\Delta$ CFI \\
\hline Configural invariance & $2.74(370)$ & 0.90 & 0.80 & $0.048(0,045-0,052)$ & 0.01 \\
Metric invariance & $2.67(389)$ & 0.90 & 0.83 & $0.047(0,045-0,051)$ & 0.01 \\
Scalar invariance & $2.64(408)$ & 0.89 & 0.87 & $0.047(0,043-0,050)$ & 0.02 \\
\hline
\end{tabular}


Brazilian samples, in which reverse items (13, 20 and 23) were also excluded from the final solutions (Fidelis, 2016; Raulino, 2015), corroborating studies that pointed that inverted items tend to be problematic in evaluating a positive construct, such as PCQ-24 (Avey et al., 2011, Dawkins et al., 2013, Luthans \& Youssef-Morgan, 2017). Raulino (2015) pointed out that these are the only negative items of the scale and can be interpreted as pessimism, contrasting with the other factors predicted in the instrument.

The occurrence of a negative statement is not merely the reverse of the positive affirmation. It is possible that, in Brazilian culture, the meaning of "no" is different from that of the American culture, where the questionnaire was developed. The influence that cultural norms (individualism or collectivism, for example) and that social desirability can have on the patterns of responses should be considered (Rego et al., 2010; Raulino, 2015).

In this study, the results point to the existence of a latent second-order factor, called PsyCap, which is formed from the interaction of the four first-order factors. Thus, it corroborates the theoretical proposal of Luthans et al., (2007), which predicts the existence of a latent state of PsyCap and also international studies that demonstrate that PsyCap is a second-order factor, which fits better than the four-factor model (Avey et al., 2008, Suthi et al., 2007), and in the literature (Lanceans et al., 2008). It is noticed that the studies developed in the group led by the author of the original scale, as well as others conducted in parts of Europe and Asia, have confirmed the second-order structure of PsyCap, such as the one identified in this study.

In Brazil and in the Portuguese language, however, it is emphasized that no previous study has empirically verified the second-order factorial structure, and the previous results are inconsistent, with structures of 4 or 5 factors (Antunes et al., 2017; Fidelis, 2016; Formiga et al., 2014; Raulino, 2015; Rego et al., 2010; Viseu et al., 2012).

The invariance of the male and female models revealed a good fit for both groups. Therefore, the results showed a configural, metric and scalar invariance of the PCQ-24 in the second-order model with 21 items, since the differences caused by the restrictions were practically irrelevant and were not statistically significant for the female and male groups. Similar results were found in the study by Kamei et al., (2018) testing the invariance of PCQ-12 in Brazil for samples independent of sex and age.
The interpretation of the results obtained should take into account some limitations of the empirical research, although they do not obscure the relevance of the study: a) the sample was composed of participants from all regions of Brazil, although the generalization capacity of the results obtained is restricted, since the sample consisted predominantly of participants residing in the southeast region $(67 \%)$; b) only by workers, which makes it difficult to apply to other contexts; c) the choice of sample was by convenience sampling and not probabilistic in the study; d) data collection was performed in a single moment; e) the scale is a translation of an English language instrument, subject to cultural bias, which may compromise the correspondence of some items to the Brazilian context.

This study makes a great contribution to the theory that argues that PsyCap is a second-order factor, which consists of the synthesis of four dimensions: self-efficacy, optimism, resilience and hope. The psychometric indicators demonstrate the accuracy of the model with satisfactory indexes, the reliability of the factorial structure, the internal consistency of the PCQ-24 and corroborate the propositions of Luthans et al., (2007), evidencing it as an adequate measure to evaluate PsyCap in Brazilian workers.

\section{Final Considerations}

PsyCap has demonstrated an important construct to understand the human behavior in the organizational context, being a competitive and strategic differential of the organizations. More importantly, it is the evidence that its results are positive both for organizations and their collaborators. This capacity of positive adaptation seems to be fundamental in scenarios of recession, financial instability and unpredictability, such as that of the current Brazilian economy.

This research represents the first confirmatory study of factorial validation of the PCQ-24 in Brazil, an instrument widely used in different countries and cultures in the measurement of the construct. In the present analysis, it was evidenced that the second order theoretical factorial structure is adequate to the data observed through the structural equation models. This type of analysis is of great value in the process of revising factorial structures, refinement of psychological instruments and confirmation of theory. In addition, evaluating PsyCap as a one-dimensional variable facilitates the use of this instrument in more complex analyzes, common in the area of Psychology. 
Although the scale presented favorable psychometric evidence, it is recommended that future research continue to seek psychometric validation, given the presence of controversial results in relation to its factorial structure in the previous literature. Studies on convergent, discriminant, and concurrent validity may be useful in consolidating the validity of PCQ-24. Surveys should be performed using models that compare the factorial structures of PCQ-24 (three factors, four factors, five factors, and unifatorial), as well as others that compare PCQ-12 and PCQ-24.

As the results of PsyCap are not necessarily consistent in all contexts and countries, there is a need for studies on the impact of cultural factors for the evaluation of the construct, such as cross-cultural validations and replications of the PCQ-24 in different contexts, with probabilistic samples, taking into account the more specific aspects of each culture. One can also evaluate its temporal stability by analyzing the magnitude, the fluctuation with time or historical events. It is recommended the use of PCQ-24 as an instrument to investigate the role of PsyCap in organizational behavior, taking into account its limitations, but mainly its psychometric quality, demonstrated in the present study for the Brazilian context.

\section{References}

Antunes, A. C., Caetano, A., \& Pina-Cunha, M. (2017). Reliability and construct validity of the Portuguese version of the Psychological Capital Questionnaire. Psychological Reports, 120(3), 520-536. doi: 10.1177/0033294116686742

Arbuckle, J. L. (2013). IBM SPSS AMOS User's Guide. Chicago, IL: Small Waters Corporation.

Avey, J. B., Luthans, F., \& Mhatre, K. (2008). A call for longitudinal designs in POB and PsyCap research. Journal of Org. Behavior, 29, 1-7. doi: 10.1002/ job. 517

Avey, J. B., Reichard, R. J., Luthans, F., \& Mhatre, K. H. (2011). Meta-analysis of the impact of positive psychological capital on employee attitudes, behaviors, and performance. Human Resource Development Quarterly, 22(2), 127-152. doi: 10.1002/hrdq.20070

Azanza, G., Domínguez, A. J., Moriano, J. A., \& Molero, F. J. (2014). Capital psicológico positivo: Validación del cuestionario PCQ en España. Anales de Psicología, 30(1), 294-301. doi: 10.6018/analesps.30.1.153631
Bandura, A. (1997). Self-efficacy: The exercise of control. New York, NY, US: W H Freeman/Times Books/ Henry Holt \& Co.

Cavalcante, M., Siqueira, M., \& Kuniyoshi, M. (2015). Engajamento, bem-estar no trabalho e capital psicológico: Um estudo com profissionais da área de gestão de pessoas. Pensamento \& Realidade, 29(4), 42-64. Recuperado de: revistas.pucsp.br/index. php/pensamentorealidade/article/view/22391

Çetin, F., \& Basim, H. N. (2012). Organizational psychological capital: A scale adaptation study. Review of Public Administration, 6(1), 159-179. Recuperado de http://www.todaie.edu.tr/resimler/ekler/ab48d27456a2882_ek.pdf?dergi $=$ Review $\% 20$ of $\% 20$ Public\%20Administration

Chen, D. J., \& Lim, V. K. (2012). Strength in adversity: The influence of psychological capital on job search. Journal of Organizational Behavior, 33(6), 811 839. doi: 10.1002/job.1814

Dawkins, S., Martin, A., Scott, J., \& Sanderson, K. (2013). Building on the positives: A psychometric review and critical analysis of the construct of psychological capital. Journal of Occupational and $\mathrm{Or}$ ganizational Psychology, 86(3), 348-370. doi: 10.1111/ joop.12007

Dollwet, M., \& Reichard, R. (2014). Assessing crosscultural skills: validation of a new measure of cross-cultural psychological capital. The International Journal of Human Resource Management, 25(12), 1669-1696. doi: 10.1080/09585192.2013.845239.

Du Plessis, Y., \& Barkhuizen, N. (2012). Psychological capital, a requisite for organizational performance in South Africa. South African Journal of Economic and Management Sciences, 15(1), 16-30. doi: 10.4102/ sajems.v15i1.122

Fidelis, A. C. F. (2016). Relações entre capital psicológico e motivação: Um estudo em organizações de saúde do Rio Grande do Sul. (Dissertação de mestrado). Programa de Pós-Graduação em Administração. Universidade de Caxias do Sul, Caxias do Sul, Brasil. Recuperado de: https://repositorio.ucs.br/ xmlui/handle/11338/1179

Formiga, N. S., Viseu, J., \& Neves de Jesus, S. (2014). Verificação empírica de uma medida do capital psicológico positivo em trabalhadores brasileiros. Eureka, 11, 1-18. Recuperado de: 
psicoeureka.com.py/sites/default/files/articulos/eureka-11-2-16.pdf

Görgens-Ekermans, G., \& Herbert, M. (2013). Psychological capital: Internal and external validity of the Psychological Capital Questionnaire (PCQ-24) on a South African sample. South African Journal of Industrial Psychology, 39(2), 1-12. doi: 10.4102/sajip. v39i2.1131. gorgens

Hair, J. F., Black, W. C., Babin, B. J., Anderson, R. E., \& Tatham, R. L. (2010). Multivariate data analysis. USA: Pearson Prentice Hall.

Harms, P. D., \& Luthans, F. (2012). Measuring implicit psychological constructs in organizational behavior: An example using psychological capital. Journal of Organizational Behavior, 33(4), 589-594. doi: 10.1002/job.1785

Kamei, H., Ferreira, M., Valentini, F., Peres, M., Kamei, P., \& Damásio, B. (2018). Psychological Capital Questionnaire - Short Version (PCQ-12): Evidence of validity of the Brazilian version. Psico-USF, 23(2), 203-214. doi: 10.1590/141382712018230202

Kline, R. (2015). Principles and practice of structural equation modeling. New York: Guilford Press.

Lorenz, T., Beer, C., Pütz, J., \& Heinitz, K. (2016). Measuring psychological capital: Construction and validation of the compound PsyCap scale (CPC12). PloS One, 11(4), 1-17. doi: 10.1371/journal. pone. 0152892

Luthans, F., Avey, J., Clapp-Smith, R., \& Li, W. (2008). More evidence on the value of Chinese workers' psychological capital: A potentially unlimited competitive resource? The International Journal of Human Resource Management, 19(5), 818-827. Recuperado de: http://digitalcommons.unl.edu/ managementfacpub/133

Luthans, F., \& Youssef-Morgan, C. M. (2017). Psychological Capital: An evidence-based positive approach. Annual Review of Organizational Psychology and Organizational Behavior, 4, 339-366. doi: 10.1146/annurev-orgpsych-032516-113324

Luthans, F., Avey, J. B., \& Patera, J. L. (2008). Experimental analysis of a web-based training intervention to develop positive psychological capital. Academy of Management Learning \& Education, 7(2), 209-221. doi: 10.5465/AMLE.2008.32712618
Luthans, F., Avolio, B. J., Avey, J. B., \& Norman, S. M. (2007). Positive psychological capital: Measurement and relationship with performance and satisfaction. Personnel Psychology, 60(3), 541-572. doi: 10.1111/j.1744-6570.2007.00083.x

Luthans, F., Youssef, C. M., \& Avolio, B. J. (2007). Psychological capital: Investing and developing positive organizational behavior. Positive Organizational Behavior, 1(2), 9-24. doi: 10.4135/9781446212752.n2

Luthans, F., Youssef, C. M., Sweetman D., \& Harms, P. (2013). Meeting the leadership challenge of employee well-being through relationship PsyCap and health PsyCap. Journal of Leadership and Organizational Studies, 20, 114-29. doi: $10.1177 / 1548051812465893$

Luthans, F., Youssef-Morgan, C. M., \& Avolio, B. J. (2015). Psychological capital and beyond. USA: Oxford University Press.

Marôco, J. (2014). Análise de equações estruturais: Fundamentos teóricos, software \& aplicações (2nd ed.). Pêro Pinheiro, Portugal: Report Number.

Masten, A. S. (2001). Ordinary magic: Resilience processes in development. American Psychologist, 56(3), 227. doi: 10.1037/0003-066X.56.3

Naotunna, S. (2015). Psychological capital: A positive approach to enhance commitment to change among university students. American Journal of Educational Research, 3(6), 765-769. doi: 10.12691/ education-3-6-16.

Newman, A., Ucbasaran, D., Zhu, F., \& Hirst, G. (2014). Psychological capital: A review and synthesis. Journal of Organizational Behavior, 35, 120-38. doi: $10.1002 /$ job.1916

Parker, S. (1998). Enhancing role-breadth self-efficacy: The roles of job enrichment and other organizational interventions. Journal of Applied Psychology, 83, 835-852.

Paterson, T. A., Luthans, F., \& Jeung, W. (2014). Thriving at work: Impact of psychological capital and supervisor support. Journal of Organizational Behavior, 35(3), 434-446. doi: 10.1002/job.1907

Qingshan, H., Le, L., \& Xuansheng, C. (2014). Research of employees' psychological capital structure under the background of Chinese culture. International Business Research, 7(7), 175-182. doi: 10.5539/ ibr.v7n 7 p175

Psico-USF, Bragança Paulista, v. 25, n. 1, p. 63-74, jan./mar. 2020 
Raulino, P.S (2015). Atitudes de carreira proteana e capital psicológico de gestores da saúde: um estudo em uma federação de cooperativas médicas. (Dissertação de mestrado). Programa de Pós-Graduação em Administração. Universidade de São Paulo, São Paulo, Brasil.

Rego, A., Marques, C., Leal, S., Sousa, F., \& Pina-Cunha, M. (2010). Psychological capital and performance of Portuguese civil servants: Exploring neutralizers in the context of an appraisal system. The International Journal of Human Resources Management, 21(9), 1531-1552. doi: 10.1080/09585192.2010.488459

Reichard, R. J., Dollwet, M., \& Louw-Potgieter, J. (2014). Development of cross-cultural psychological capital and its relationship with cultural intelligence and ethnocentrism. Journal of Leadership \& Organizational Studies, 21(2), 150-164. doi: 10.1177/1548051813515517

Rus, C. L., Baban, A., Jesus, S. N., \& Andrei, D. (2012). An analysis of the psychometric properties of the Psychological Capital Questionnaire-12. Journal of Educational Sciences and Psychology, 2(1), 110-122. Recuperado de: http://jesp.upg-ploiesti.ro/index. php?option $=$ com_phocadownload $\&$ view $=$ file $\&$ $\mathrm{id}=358$ :an-analysis-of-the-psychometric-properties-of-the-psychological-capital-questionnaire$12 \&$ Itemid $=16$

Sapyaprapa, S., Tuicomepee, A., \& Watakakosol, R. (2013). Validation of Psychological Capital Questionnaire in Thai Employees. The Asian Conference on Psychology \& Behavioral Sciences Official Conf. Proceedings, 394-399. Recuperado de: http://www. iafor.org/archives/offprints/acp2013-offprints/ ACP2013_0328.pdf

Scheier, M.F. \& Carver, C.S. (1985). Optimism, coping, and health: Assessment and implications of generalized outcome expectancies. Health Psychology, 4, 219-247.

Schneider, S. L. (2001). In search of realistic optimism: Meaning, knowledge, and warm fuzziness. American Psychologist, 56(3), 250. doi: 10.1037/0003-066X.56.3.250

Seligman, M. E. P. (1998). Learned optimism. New York: Pocket Books.

Siqueira, M. M. M., Martins, M. C. F., \& Souza, W. S. (2014). Capital Psicológico no trabalho. Em M. M.
M. Siqueira. (Org.). Novas medidas do comportamento organizacional: Ferramentas de diagnóstico e de Gestão (pp. 65-78). Porto Alegre: Artmed.

Snyder, C. R. (Ed.). (2000). Handbook of hope: Theory, measures, and applications. San Diego: Academic Press.

Snyder, C.R., Sympson, S., Ybasco, F., Borders, T., Babyak, M., \& Higgins, R. (1996). Development and validation of the state hope scale. Journal of Personality and Social Psychology, 70, 321-335.

Stajkovic, A. D. (2006). Development of a core confidence-higher order construct. Journal of Applied Psychology, 91(6), 1208. doi: 10.1037/0021-9010.91.6.1208

Teixeira, E. M. (2015). O impacto da liderança autêntica no capital psicológico dos colaboradores (Dissertação de mestrado). Faculdade de Economia. Universidade de Coimbra, Coimbra, Portugal.

Tabachnick, B. G., \& Fidell, L. S. (2013). Using multivariate statistics. Boston: Pearson.

Valentini, F., \& Damásio, B. F. (2016). Variância média extraída e confiabilidade composta: Indicadores de precisão. Psicologia: Teoria e Pesquisa, 32(2), 1-7. doi: 10.1590/0102-3772e322225

Viseu, J., Jesus, S. N., Rus, C., Nunes, H., Lobo, P., \& Cara-Linda, I. (2012). Capital Psicológico e sua avaliação com o PCQ-12. ECOS - Estudos Contemporâneos da Subjetividade, 2(1), 4-16. Recuperado de: www.periodicoshumanas.uff.br/ecos/article/ view/792/666

Wagnild, G. M. \& Young, H. M. (1993). Development and psychometric evaluation of the resiliency scale. Journal of Nursing Management, 1(2), 165-178.

Wernsing, T. (2014). Psychological capital: a test of measurement invariance across 12 national cultures. Journal of Leadership \& Organizational Studies, 21(2), 179-190. doi: 10.1177/1548051813515924

Youssef, C. M., \& Luthans, F. (2007). Positive organizational behavior in the workplace: The impact of hope, optimism, and resilience. Journal of Management, 33(5), 774-800. doi: 10.1177/0149206307305562

Recebido em: 30/12/2017 Reformulado em: 15/10/2018, 16/01/2019 Aceito: 28/01/2019 
About the authors:

Daren Tashima Cid - Psychologist graduated from the Universidade Federal de Uberlândia, holds a Masters in Psychology from the Universidade de Brasilia. PhD student in Health Psychology at Universidade Metodista de São Paulo. Completed a Sandwich PhD stay at Universidade de Coimbra.

ORCID: https://orcid.org/0000-0001-7202-9126

E-mail: darentashimacid@gmail.com

Maria do Carmo Fernandes Martins - Psychologist graduated from Universidade de São Paulo, holds a Masters and $\mathrm{a} \mathrm{PhD}$ in Psychology from the Universidade de Brasilia. Lecturer and Coordinator of the Graduate Program in Health Psychology at the Universidade Metodista de São Paulo, São Bernardo do Campo, state of São Paulo.

ORCID: https://orcid.org/0000-0002-5950-6554

E-mail:mcf.martins@uol.com.br

Maiango Dias - Psychologist and Master in Applied Psychology from the Universidade Federal de Uberlândia. PhD student in Health Psychology at the Universidade Metodista de São Paulo, and lecturer at the Department of Social and Institutional Psychology at Universidade Estadual de Londrina.

ORCID: https://orcid.org/0000-0001-7788-536X

E-mail:maiango@yahoo.com

Andrea Cristina Fermiano Fidelis - Psychologist graduated from the Universidade do Vale do Rio dos Sinos, holds a Masters in Business Administration from the Universidade de Caxias do Sul, and is a PhD student in Marketing and Strategy at the Universidade de Aveiro, Portugal.

ORCID: https://orcid.org/0000-0003-0089-3681

E-mail: acris.fidelis@gmail.com

Contact:

Rua Piratini, 53

Catanduva-SP, Brasil

CEP: $15807-240$ 